Malaysian Journal on Composite Science and Manufacturing

\title{
Optimization of Hot Press Parameters to Maximize the Physical and Mechanical Properties of Natural Rubber Composites for Elastomeric Mount
}

Anis Aqilah Abd Ghani ${ }^{1}$, Noraiham Mohamad ${ }^{1,}{ }^{*}$, Jeefferie Abd Razak ${ }^{1}$, Qumrul Ahsan ${ }^{1}$, Chang Siang Yee $^{1}$, Muhammad Afiq Ani ${ }^{2}$, Ming Ming Teng ${ }^{2}$, Anwar Ul-Hamid ${ }^{3}$

Fakulti Kejuruteraan Pembuatan, Universiti Teknikal Malaysia Melaka, 76100 Durian Tunggal, Melaka, Malaysia

HML Auto Industries (M) Sdn Bhd, Taman Jati, 45800 Kapar, Selangor, Malaysia

Center for Engineering Research, Research Institute, King Fahd University of Petroleum \& Minerals, Dhahran 31261, Saudi Arabia

\section{ARTICLE INFO}

\section{Article history:}

Received 30 November 2019

Received in revised form 30 February 2020

Accepted 15 March 2020

Available online 30 March 2020

\section{Keywords:}

Optimization, Hot Press, Natural Rubber

Composites, Response Surface

Methodology

\section{ABSTRACT}

Optimum processing parameters are highly important to the performance and processability of an elastomeric mount. A commercial black natural rubber compound of an elastomeric mount investigated for the effect of curing and hot press parameters towards maximizing the physical and mechanical properties. The parameters such as the pressing temperature $\left(140-180^{\circ} \mathrm{C}\right)$, pressure $\left(100-140 \mathrm{~kg} / \mathrm{cm}^{2}\right)$ and curing time $(5$ to 15 minutes) screened using a response surface methodology technique via a two level factorial design. These parameters were the independent variables and the tensile properties, hardness and density were the responses. The coefficient of determination, $R^{2}$ values for all responses were very close to the unity of $0.90-0.99$ hence almost $100 \%$ of the variation in the overall system were presented by the model. The optimum calculated values of the tested variables for the maximum physical and mechanical properties were found to be at a pressing temperature of $140^{\circ} \mathrm{C}$, pressure of $140 \mathrm{~kg} / \mathrm{cm}^{2}$ and a curing time of 15 minutes with a predicted tensile strength of 21.74 MPa and hardness of 15.43 Shore A.

Copyright @ 2020 PENERBIT AKADEMIA BARU - All rights reserved

\section{Introduction}

Engine mount is an essential automotive component that holds the engine of the car and there usually three or four mounts that bolted together with the engine of the car (Figure 1). It consists of 2 parts; 1 part of it is bolted to the chassis and the other one is holding the engine [1]. According to Yu et al. [2], engine mount helped to support the weight of the engine and distributes the load

\footnotetext{
* Corresponding author.

E-mail address: noraiham@utem.edu.my (Noraiham Mohamad)
} 
uniformly to the chassis and this is the basic function of engine mounting system. Another important role is to reduce the dynamic force, noise and shock excitation so that it helps to give driving stability [3-4]. According to Martyr and Plint [5] a good engine mount system is needed to reduce the transmission of the engine vibration to the car body. Furthermore, it should be able to withstand the temperature above $80^{\circ} \mathrm{C}$ up to $100^{\circ} \mathrm{C}$ as well as aggressive substances such as oil and cleaning liquid.

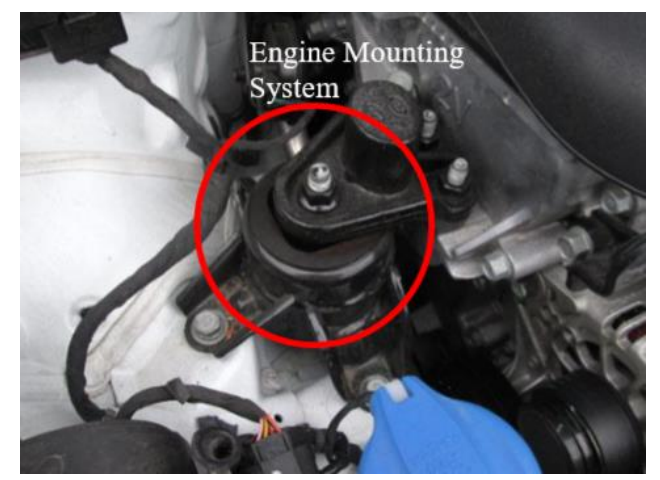

Fig. 1. Engine mount (samarins.com)

There is numerous type of engine mounts; active, semi-active and passive engine mounts. The passive mount consists of elastomeric (rubber) and hydraulic types. Since 1930s, researchers have been traditionally used passive engine mounts made from rubber to reduce the vehicle vibration from the engine and the chassis [8]. Elastomeric mounts are the first generation of engine mounts [6]. Hossein [7] and Yu et al. [2] stated that these mounts have simple designs, compact, cost effective, free from maintenance and durable. Moreover, elastomeric engine mounts are versatile and can be designed to have required elastic stiffness in all specs for appropriate vibration isolation. The drawbacks, this conventional rubber mount cannot satisfy the excitation frequencies of $1-250 \mathrm{~Hz}$ and the amplitudes because the changed for inserted stiffness and viscous damping are nearly zero [8]. Therefore, there are numerous improvement and advancement explored by researchers to increase the performance of these elastomeric mounts [2]. In current day, due to evolution of vehicles and engines the elastomeric-based passive engine mounts used the combination of rubberto-metal that joined. In this system, the rubber compound (usually natural rubber) bonded to metal parts (usually steel) during a vulcanization process. When vulcanized, it will form an elastomer that is elastic and dimensionally stable. The elastomer can deform under stress but return to its original shape when the stress is relieved.

Natural rubber (NR) composites have abundant benefits and one of its main application is in the production of an elastomeric-based passive engine mounting. According to Santhosh et al. [9], there are plenty of types of rubber suitable to isolate the vibration in the passive engine mounts system. For instance, nitrile rubber (NBR), polybutadiene rubber (PR), natural rubber (NR), epoxidized natural rubber (ENR), polyurethane (PU), nano clay-modified polypropylene, six blends system and others which range from natural, synthetic or blends. In general, NR widely utilized as the rubber mount material because of its elastic hydrocarbon chains originated from naturally occurring latex, in the sap of hevea brasiliensis plants [10]. The NR provides relatively high strength, outstanding fatigue resistance, good tear resistance and excellent resilience, good resistance to creep and low sensitivity to strain effects in dynamic applications. In this regards, it is used in elastomeric material since 1930s, and be the most popular, affordable to be used as the rubber parts even for today [11].

However, many researchers did not suggest NR exposed to the atmosphere with high temperature due to their relatively low thermal and ozone resistance than some of the synthetic rubber system, which made from petroleum [12]. In contrast, the petroleum-based rubber is non- 
eco-friendly, relatively low strength and non-economical which still placed the NR as the rubber of choice in an engine mounting system. According to Wang et al. [11], for the elastomeric part, the NR serves as a matrix and their molecular chains chemically bond together with organic or non-organic fillers under suitable mixing heat and pressure. Once vulcanized, it is suitable to use in the engine mount systems.

Adhau and Kumar addressing the concern of vibrations and noises, which originated from the engine, the largest concentrated mass in the vehicle if it is not properly constrained and isolated from the chassis [13]. In severe cases, it could damage the engine and gear box components if the quality parameters such as suitable materials' formulation, design, joining types and processing parameters ignored by the manufacturer. Some of the existing engine mounts in the market also have unsuitable characteristic for the rubber part due to wrong formulation, improper processing parameters and weak rubber-to-metal join due to inadequate adhesive bonding strength. Manufacturers preferred to use glue rather than in-situ chemically vulcanization bonding. Moreover, they do not perform the fatigue tests at operating temperature and thus no information of the rubber fatigue properties.

According to Mukooza, for an optimum service condition, the most of the engine mounts will last long until five to seven years only [14]. There are cases where the mounting system deteriorates prematurely in about 2 years when the rubber part breaks or when the liquid inside it starts to leak. NoorAzammi et al. agreed with the importance of enhancing the properties of engine mount without increasing the overall cost, altering the materials, and changing the process line via selection of suitable design [15]. Therefore, maximizing the rubber parts properties by a proper design of experiment is crucial; whether during the compounding or fabrication/vulcanization process. The fabrication of the rubber composite parts by hot press, injection molding or compression molding technique can be planned, analyzed and evaluated using a suitable design of experiment (DOE) tool. The parameters involved in the process such as mixing speed, temperature, pressure and time should be optimized.

Optimization of processing parameters is a vital engineering step, which normally overlooked by engine mount manufacturers and leaves a big gap between the existing researches. There are range of processes available in industries however; the literature on optimization of processing parameters specific for engine mount is scarce. Not only it could help manufacturers to identify the optimum parameters, it will help to achieve the maximum mechanical and physical properties of the rubber parts within the shortest possible time. According to Mohamad et al., optimization is a statistical and mathematical approach by using the suitable tools [16]. Meanwhile, Juliana [17] introduces some literatures that investigated the optimization of processing parameters on the properties of NR based composites to overcome the unverified processing parameters for NR compound. Mohamad et al. [16] stated that optimization is less time consuming and able to detect true optimum of the process condition. Through this methodology, the interaction between input parameters could be determined and able to find the optimum value of responses.

This study focuses on the screening methodology of processing parameters using Response Surface Methodology (RSM) for the optimization purposes. A set of experiment was designed using a two level factorial design, analyze and further evaluate with the help of a Design Expert software. The commercial grade NR compound supplied by HML Auto Industries (M) Sdn Bhd. Thus, the study is mainly focusing on the optimization of hot press processing parameters to maximize the mechanical and physical properties of the fabricated vulcanized NR composites. The parameters tested were (1) temperature: $140-180{ }^{\circ} \mathrm{C}$; (2) pressure: $100-140 \mathrm{~kg} / \mathrm{cm}^{2}$ and (3) curing time: $5-15$ minutes. The design matrix, analysis of variance, regression test and optimization generated using a Design Expert Software Version 6.0.8. 


\section{Methodology}

\subsection{Natural rubber compound}

Natural rubber compound, NR 60 grade supplied by HML Auto Industries Sdn Bhd (Figure 2). This compound is technically specified NR compound used in the manufacturing of high-performance engine mountings, tires, conveyer belts and mostly in general rubber products. It has low viscosity properties; therefore, it can reduce the mixing period considerably making it a very efficient material.

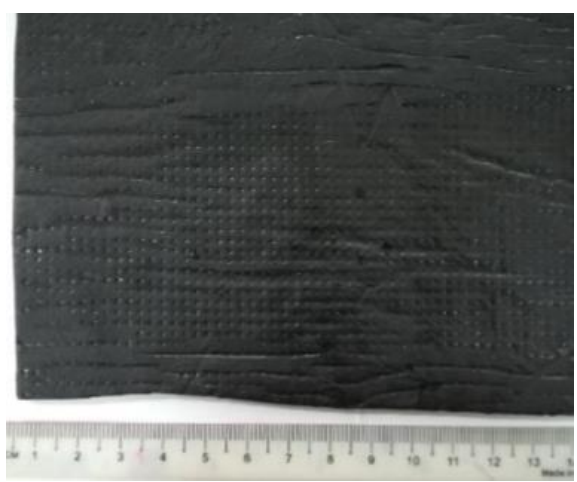

Fig. 2. Natural Rubber Compound

\subsection{Designing the Processing Parameters Using Response Surface Methodology (RSM)}

Design of experiments is carried out using a Design Expert Software (Statistics Made Easy, version 6.0.8 Portable). Two-level factorial design of three factors experiment utilized in this study. There were 11 experiments with three replications at center point. Table 1 shows the level of variables in this study while Table 2 shows the design matrix for two level factorial design of all independence variables.

Table 1

Level of Variables

\begin{tabular}{ccc}
\hline Temperature $\left(\mathrm{X} 1 ;{ }^{\circ} \mathrm{C}\right)$ & Pressure $\left(\mathrm{X} 2 ; \mathrm{kg} / \mathrm{cm}^{2}\right)$ & Curing time $(\mathrm{X} 3 ; \mathrm{min})$ \\
\hline $140(-1)$ & $100(-1)$ & $5(-1)$ \\
$160(0)$ & $120(0)$ & $10(0)$ \\
$180(+1)$ & $140(+1)$ & $15(+1)$ \\
\hline
\end{tabular}

Table 2

Two Level Factorial Design $2^{3}$

\begin{tabular}{cccc}
\hline Experiment No & Temperature $\left(\mathrm{X} 1 ;{ }^{\circ} \mathrm{C}\right)$ & Pressure $(\mathrm{X} 2 ; \mathrm{kg} / \mathrm{cm} 2)$ & Curing time $(\mathrm{X} 3 ; \mathrm{min})$ \\
\hline 1 & -1 & -1 & -1 \\
2 & +1 & -1 & -1 \\
3 & -1 & +1 & -1 \\
4 & +1 & +1 & -1 \\
5 & -1 & -1 & +1 \\
6 & +1 & -1 & +1 \\
7 & -1 & +1 & +1 \\
8 & +1 & +1 & +1 \\
9 & 0 & 0 & 0 \\
10 & 0 & 0 & 0 \\
11 & 0 & 0 & 0 \\
\hline
\end{tabular}


By using RSM of two-level full factorial, $2^{3}$ (refer Table 2), the effect of processing parameters could be systematically evaluated. The independent variables were temperature $(X 1)$, pressure $(X 2)$ and cure time (X3). Mechanical and physical properties selected as the responses and indicated as dependent variables; tensile strength, TS (Y1); elongation at break, EB (Y2); modulus as $100 \%$ elongation, m100 (Y3); modulus at 300\& elongation, m300 (Y4); density (Y5); hardness (Y6) and swelling (Y7). From the experimental findings, polynomial relationships for all responses obtained. The result of this design used to fit a first-order polynomial, which included all interaction terms as shown in Eq. 1;

$$
Y=\beta 0+\beta 1 \times 1+\beta 2 \times 2+\beta 3 \times 3+\ldots+\beta n \times n+\varepsilon
$$

where $Y$ is the predicted response; $B$ is the coefficient values; $x$ is the independent variables and $\varepsilon$ is a random error. In this study, $k=3$ was used because there were three independent variables involved. The mathematical relationship connecting the three variables and the response from Eq. 2 becomes;

$Y=B 0+B 1 X 1+B 2 X 2+B 3 X 3+B 12 X 1 X 2+B 13 X 1 X 3+B 23 X 2 X 3$

where $Y$ is still the predicted response; $B O$ is the offset term; $B 1, B 2$ and $B 3$ are the linear coefficients; $B 12, B 13$ and $B 23$ are the cross product coefficient; and $X 1, X 2$ and $X 3$ are the independent variables. The model selected for each response based on the high priority in accordance with the polynomial level and the lowest $P$ value. From the RSM, a regression equation for the selected model for the response, $Y$ derived.

\subsection{Fabrication using Hot Press Machine}

The as-received NR compound cut into smaller pieces and carefully filled into a rectangular mold cavity to undergo curing process. Then, the NR compound compressed using GT7014-A hot press with ranges of temperature, time and pressure generated by the software. Along with the shaping, the fabricated sheets vulcanized with vulcanization system premixed in the as-received NR compound. The thickness of the NR composites varied based on the requirement of tensile test and hardness test.

\subsection{Physical and Mechanical Testing}

The vulcanized sheets of $1 \mathrm{~mm}$ thick cut into Dumbbell-shaped samples using a Dumbbell die cutter with size of $63.5 \times 9.53 \mathrm{~mm}$ (Figure 3a). After the fabrication, the composites undergone tensile test using the Universal Testing Machine (Shimadzu AGS-X Series) according to ASTM D8122. It performed at a crosshead speed of $500 \mathrm{~mm} / \mathrm{min}$ in room temperature. At least seven samples tested for every set of experiments to ensure a high confidence level. The collection of data is in term of elongation at break, maximum stress and modulus.

Hardness of the NR composites sheets with the thickness of $6 \mathrm{~mm}$ measured using a Durometer Hardness (Shore A) as shown in Figure $3 \mathrm{~b}$. Reading taken at seven different locations were then average to ensure the more accurate result. Durometer is a device for measuring hardness usually for relatively soft materials such as elastomers, rubbers and plastics. The higher the scale, the higher the resistance to indentation of the materials. 


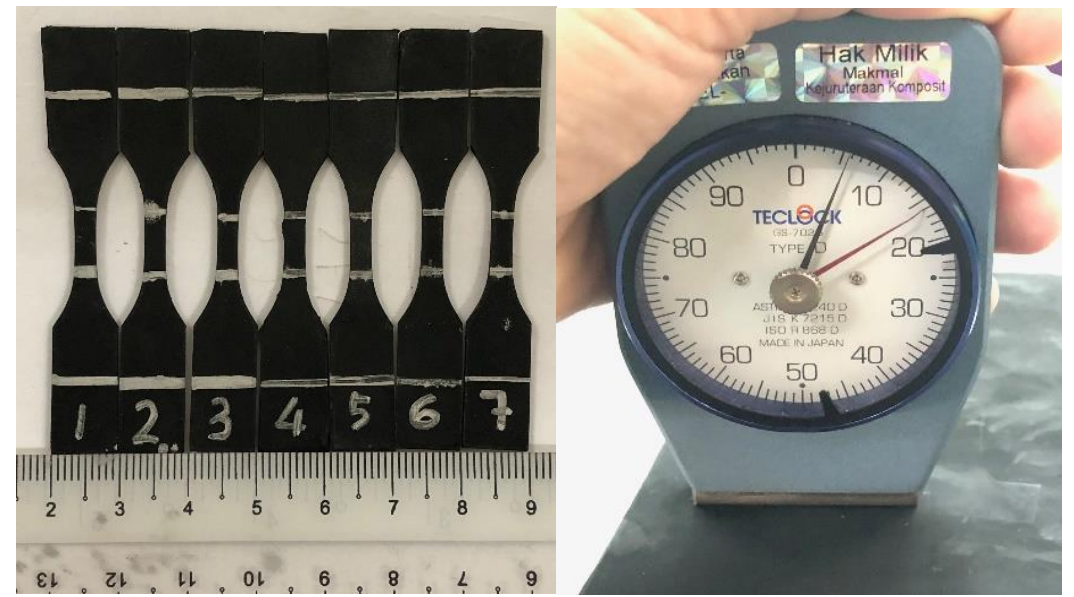

Fig. 3. (a) Dumbbell shapes NR sheets and (b) measuring of hardness using a Durometer

Meanwhile, the density of the NR composites measured according to ASTM 1895 by using an Electronic Densimeter MD-300S (AlfaMirage, Japan). To get the average value, at least three measurements taken for each sample. Despite the simplicity, this density value is important since it noticeably varies with temperature and pressure of the materials processing.

\section{Results}

\subsection{Regression Model of Factor Interactions}

The regression model for each response including all terms presented in Table 3 . The interaction effects of all independent variables to the response represents in a mathematical relationship as quantitative effect. Positive values reflect effects that lead to optimization whereas negative values provide opposite effect on the response. The $\mathrm{R} 2$ values indicate the degree of agreement between the experimental results with those predicted by model. The R2 values for all responses are obtained in the range of $0.90-0.99$ which are very close to union (R2 = 1). The model presented almost $100 \%$ of the variation in the overall system. This indicates that the regression model is accurate in describing and predicting the pattern of significance for each independent variables or factors studied.

Table 3

Regression models of all responses

\begin{tabular}{|c|c|c|c|c|}
\hline No & Response, $\mathrm{Y}$ & $\mathrm{R}^{2}$ & Adjusted $\mathrm{R}^{2}$ & Regression Model \\
\hline 1 & $\begin{array}{l}\text { Tensile } \\
\text { strength }\end{array}$ & 0.9980 & 0.9911 & $\begin{array}{l}Y_{1}=20.25-1.68 X_{1}+0.11 X_{2}+1.625 X_{3}+0.035 X_{1} X_{2}+0.47 X_{1} X_{3}- \\
0.25 X_{2} X_{3}-0.44 X_{1} X_{2} X_{3}\end{array}$ \\
\hline 2 & $\begin{array}{l}\text { Elongation } \\
\text { at break }\end{array}$ & 0.9998 & 0.9993 & $\begin{array}{l}Y_{2}=390.04-13.17 X_{1}+11.35 X_{2}-25.31 X_{3}-1.76 X_{1} X_{2}+7.06 X_{1} X_{3}- \\
4.18 X_{2} X_{3}+7.17 X_{1} X_{2} X_{3}\end{array}$ \\
\hline 3 & $\begin{array}{l}\text { Modulus } \\
100\end{array}$ & 1.0000 & 0.9999 & $\begin{array}{l}Y_{3}=4.05-0.35 X_{1}-0.090 X_{2}+0.38 X_{3}-0.040 X_{1} X_{2}-0.16 X_{1} X_{3}- \\
0.025 X_{2} X_{3}-0.22 X_{1} X_{2} X_{3}\end{array}$ \\
\hline 4 & $\begin{array}{l}\text { Modulus } \\
300\end{array}$ & 1.0000 & 0.9999 & $\begin{array}{l}Y_{4}=14.51-0.73 X_{1}-0.44 X_{2}+1.33 X_{3}-0.20 X_{1} X_{2}-0.21 X_{1} X_{3}-0.21 X_{2} X_{3} \\
-0.66 X_{1} X_{2} X_{3}\end{array}$ \\
\hline 5 & Density & 0.9994 & 0.9971 & $\begin{array}{l}Y_{5}=1.18-0.051 X_{1}-0.020 X_{2}-0.022 X_{3}+0.011 X_{1} X_{2}+0.024 X_{1} X_{3}+ \\
0.023 X_{2} X_{3}-0.039 X_{1} X_{2} X_{3}\end{array}$ \\
\hline 6 & Hardness & 0.9959 & 0.9817 & $\begin{array}{l}Y_{6}=13.10-1.24 X_{1}-0.56 X_{2}+0.025 X_{3}-0.50 X_{1} X_{2}-0.95 X_{1} X_{3}- \\
0.43 X_{2} X_{3}-0.59 X_{1} X_{2} X_{3}\end{array}$ \\
\hline 7 & Swelling & 0.9993 & 0.9967 & $\begin{array}{l}Y_{7}=124.93+0.36 X_{1}+3.83 X_{2}-12.75 X_{3}+10.27 X_{1} X_{2}-7.41 X_{1} X_{3}+ \\
4.5 X_{2} X_{3}+9.60 X_{1} X_{2} X_{3}\end{array}$ \\
\hline
\end{tabular}

3.2 Interaction between Variables for Mechanical Properties 
Table 4 summarizes the effect of processing parameters on tensile strength and hardness and further illustrate in Figure 4. The predicted tensile strength and hardness at each experimental point listed along with the experimental data. The observed close values between experimental and prediction proven that the regression model (Table 3 ) is accurate in describing and predicting the pattern of significance for the tensile strength and hardness.

In Figure 4, the tensile strength decreased with the increase of hot press temperature. This in line with the observation by Lee et al. in their study where too high vulcanization temperature reduced the mechanical properties of NR composites [18]. Temperature marked significant impact to the tensile strength while curing time and pressure contributed not too much on the changes. This behaviour is in good agreement with the SEM observation shown in Figure 6.

Referring to Table 3, temperature gives the highest contribution on the decrement of hardness value compared to other factors. This shows that the lower cross-linking leads to lower in rigidity of the composites. The decreased attributed to the main-chain scission due to oxidative degradation of NR composites [19]. M100 and M300 are the measures of rubber stiffness [20]. From the negative model term, these values decrease as curing time and temperature increase. This might be due to deterioration of the rubber chains at high pressing temperature and long curing time, resulting phenomenon called chain scissoring. As a result, increase in temperature and curing time does not improve the modulus of the NR composites. Meanwhile, from the regression model, the elongation at break (EB) for NR composites decreased as the cure time and temperature increased but the EB increased as the pressure increased. The pressure accelerates the cross-linking at suitable temperature even for a short period. It helps to postpone the premature failure by preventing chain slippage from occurring during tensile testing. Meanwhile, too high temperature and cure time may damage the rubber chain. Thus, appropriate temperature, cure time and pressure is essential to improve the mechanical properties of NR composites.

Table 4

Comparisons of Experimental and Predicted Tensile Strength and Hardness Values of NR Composites

\begin{tabular}{ccccc}
\hline \multirow{2}{*}{$\begin{array}{c}\text { Experiment } \\
\text { No. }\end{array}$} & \multicolumn{2}{c}{ Tensile strength } & \multicolumn{2}{c}{ Hardness } \\
\cline { 2 - 5 } & $\begin{array}{c}\text { Experimental value }(\mathrm{Y} ; \\
\mathrm{MPa})\end{array}$ & $\begin{array}{c}\text { Predicted value } \\
(\mathrm{Y} ; \mathrm{MPa})\end{array}$ & $\begin{array}{c}\text { Experimental value } \\
(\mathrm{Y} ; \text { Shore } \mathrm{A})\end{array}$ & $\begin{array}{c}\text { Predicted value } \\
(\mathrm{Y} ; \text { Shore } \mathrm{A})\end{array}$ \\
\hline 1 & 22.52 & 22.52 & 13.58 & 13.58 \\
2 & 17.26 & 17.26 & 12.83 & 12.83 \\
3 & 22.28 & 22.28 & 13.14 & 13.14 \\
4 & 18.93 & 18.93 & 12.75 & 12.75 \\
5 & 21.19 & 21.19 & 15.21 & 15.21 \\
6 & 19.58 & 19.58 & 13.00 & 13.00 \\
7 & 21.74 & 21.74 & 15.43 & 15.43 \\
8 & 18.50 & 18.50 & 8.86 & 8.86 \\
9 & 18.23 & 18.50 & 14.36 & 14.44 \\
10 & 18.39 & 18.39 & 14.25 & 14.44 \\
11 & 18.55 & 18.39 & 14.71 & 14.44 \\
\hline
\end{tabular}



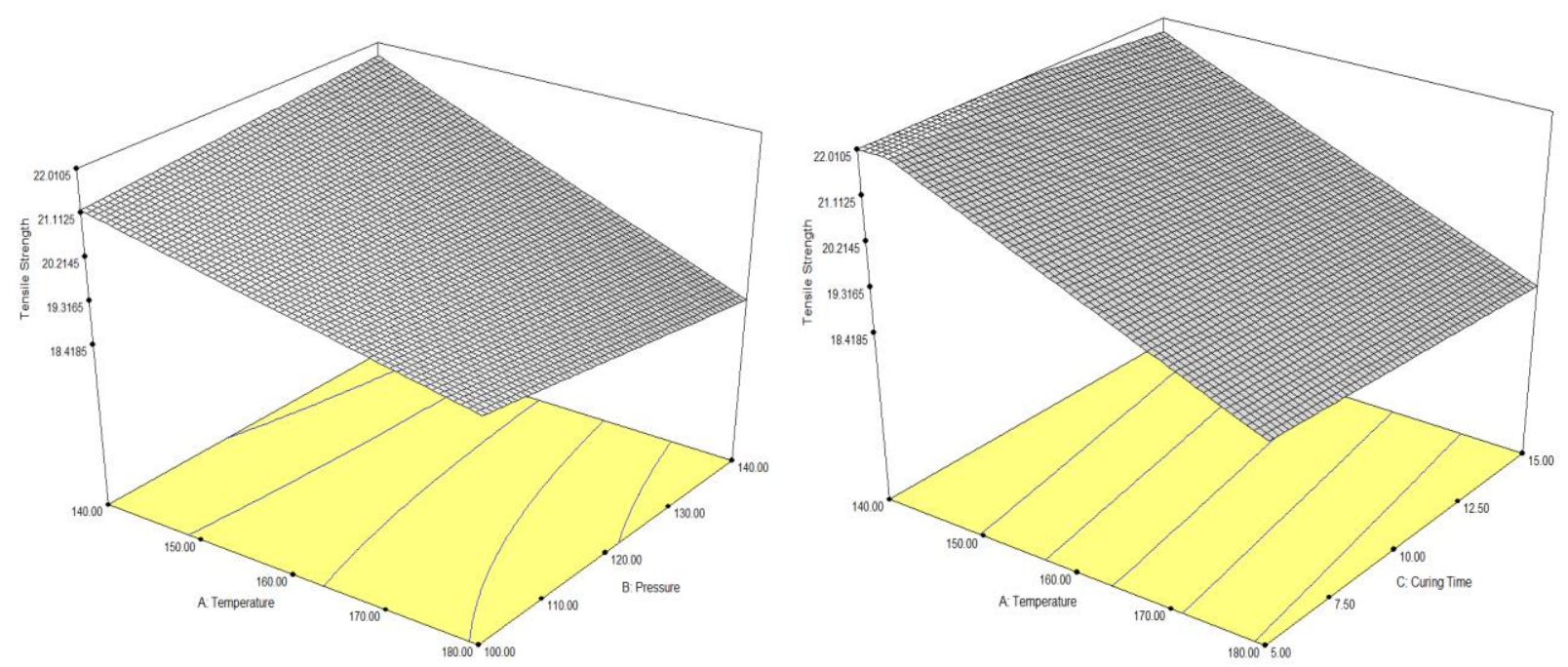

Fig. 4. (a) 3D Model of temperature and pressure interaction when curing time was set constant at 15 minutes and (b) interaction of temperature and curing time when pressure was set at $140 \mathrm{~kg} / \mathrm{m}^{2}$

By referring to Table 2 and 4, samples vulcanized at the highest temperature $(+1)$, curing time $(+1)$ and pressure $(+1)$ resulted to the minimum tensile strength and hardness, as represented by the experiment No. 8 (coded as S8). On the other hand, the maximum value of tensile strength and hardness was obtained at the lowest temperature $(-1)$ and highest pressure $(+1)$ and curing time $(+1)$ for samples in experiment No. 7 (coded as S7). The tensile and hardness of the samples were compared to categorize the samples into the best and the worst. For the worst samples, there were 2 types, 1) worst as it is uncured and 2) worst as it is over cured. The S7 chosen as the best sample as it exhibits the highest mechanical and physical properties. The S2 chosen as the worst under cured due to low curing time and pressure but high temperature. While S8 was the worst over cured sample due to the highest temperature, pressure and curing time. All the categories tabulate in Table 5.

Table 5

Category of the NR Composites based on performance

\begin{tabular}{lcccc}
\hline Category & Code & Temperature & Pressure & Cure Time \\
\hline Best & S7 & 140 & 140 & 15 \\
Moderate & S9 & 160 & 120 & 10 \\
Worst Under Cured & S2 & 180 & 100 & 5 \\
Worst Over Cured & S8 & 180 & 140 & 15 \\
\hline
\end{tabular}

\subsection{Interaction between Variables for Physical Properties}

Effects of all parameters on swelling measurement and density of the NR composites represented by the perturbation plots in Figure 5 . Swell measurements were conducted to determine the crosslink density of the NR composites respective to the combination effect of processing parameters. The most critical parameter on swelling was curing time; the swelling percentage decreased as the curing time increased. This is due to the increase in crosslink density, causing low penetration of solvents into the cured samples [18]. Mohamad et al. stated that solvent penetrate through is directly correlated to the crosslink density of a network in molecular chain. Low swelling of the NR composites in toluene indicating higher crosslink density [21]. The effect of processing parameters on density shown in Figure $5(\mathrm{~b})$ where the biggest contributor was the pressing 
temperature. Meanwhile other factors showing trivial effects to the change in density. As the temperature increased, the density of NR composites decreased. So, the lowest density obtained when curing conducted at the highest possible temperature, which might indicated lower crosslink density as observed in the swelling test.

From the point optimization for the highest TS and hardness where other properties are in range, the experiment No. 7 (coded as S7) was the selected optimum sample, which has low temperature: $140{ }^{\circ} \mathrm{C}$; high pressure: $140 \mathrm{~kg} / \mathrm{cm} 2$ and curing time: 15 minutes. This is because $\mathrm{S} 7$ has high desirability compared to others and all the testing shows that S7 is the best sample. Since engine mount manufacturer mostly preferred to choose high temperature, low pressure and low curing time (represented by S2), the rubber parts may exhibit reduction in TS and hardness of about 15 to $20 \%$.

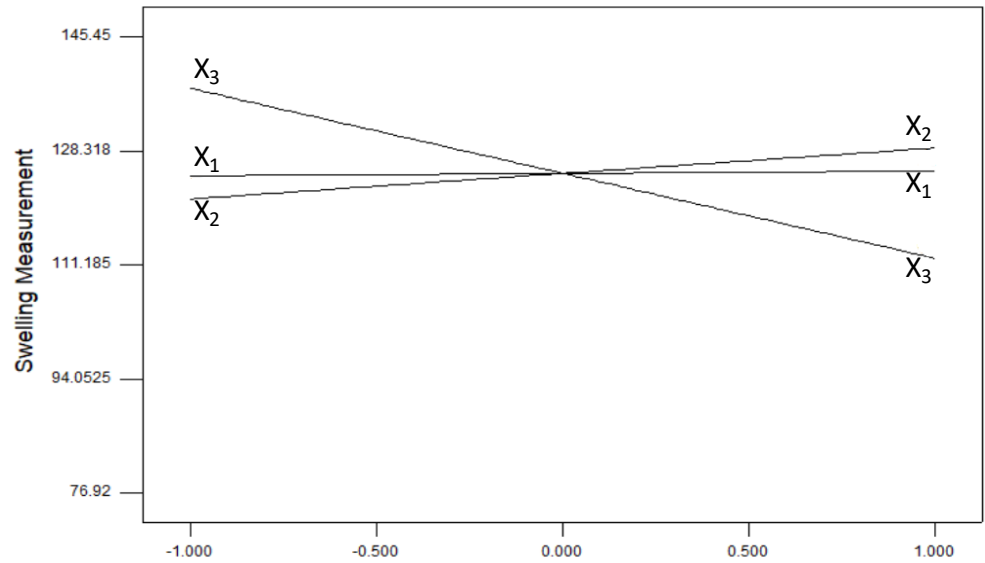

(a)

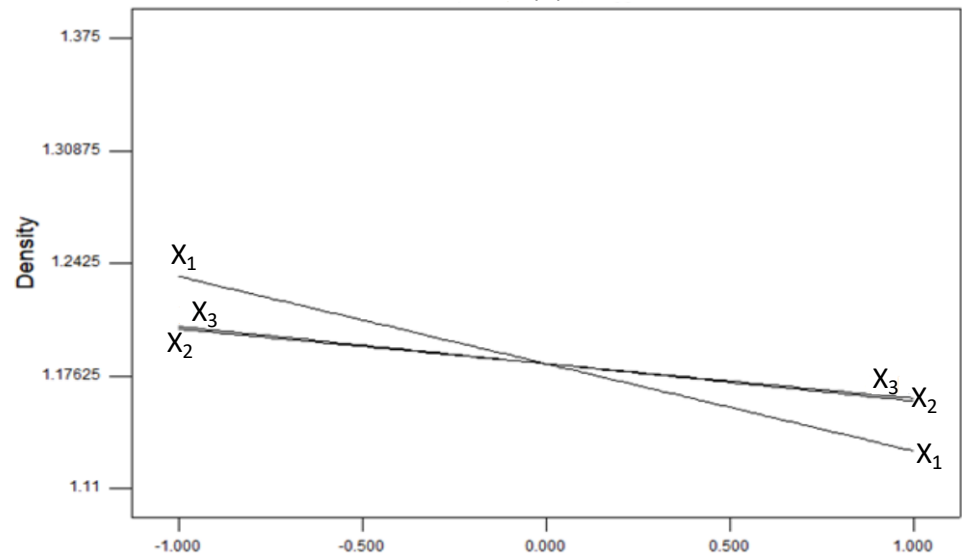

(b)

Fig. 5. Perturbation plot of all factors interaction deviation from reference point of $T=160 \mathrm{C}, P=120 \mathrm{~kg} / \mathrm{m} 2$ and $\mathrm{t}=10 \mathrm{~min}$

\subsection{Morphological Analysis on Fracture Tensile Surfaces}

Morphological analysis utilize to assess the findings from the mathematical and statistical analyses gained from the RSM. Figure 6 depicts the SEM micrographs taken from the tensile fracture surfaces of S7 (best) and S2 (worst under cured) at magnification of 500X, respectively. The morphological characteristics of NR based composites highly reflecting the behaviour of the composites under tensile stress. The surface of $\mathrm{S} 7$ exhibits much rougher surfaces with many tearing lines compared to S2 (Figure 6b). These explained good interaction and better stress transfer across the interface between the NR based composites in S7. This led to high resistance to crack propagation 
and hence, higher tensile strength. On the other hand, the worst uncured sample displays broader tearing lines, micro crack and thick fracture between phases.

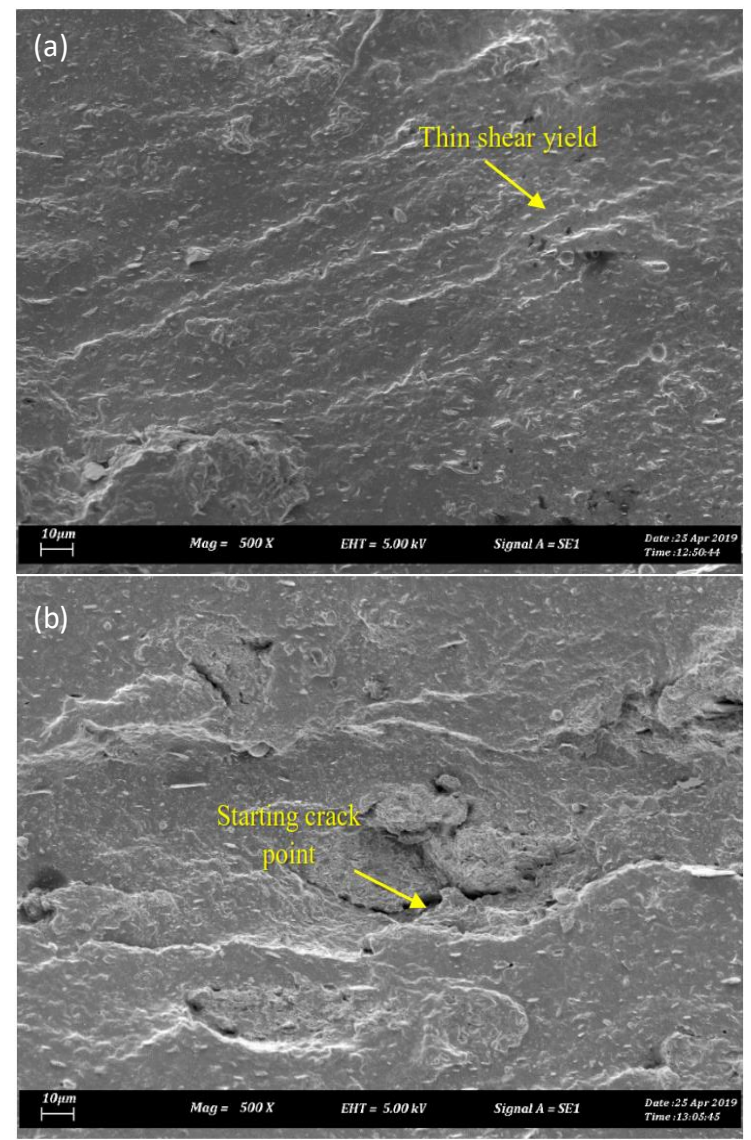

Fig. 6. SEM micrographs of tensile fracture surface of (a) S7, the best sample and (b) S2, the worst under cured sample at 500X magnifications

\section{Conclusions}

A systematic investigation using the RSM on the optimization of hot press processing parameters on the mechanical and physical properties of commercialized grade NR composites conducted. The best sample (coded as S7) obtained at the lowest pressing temperature, the highest pressure and longest cure time. It resulted in relatively maximum tensile strength, the highest hardness, low swelling percentage and low density. The values of the coefficient of determination (R2) were excellent with values of above 0.90 . The morphological analyses reflecting the findings observed in the optimization experiment where the best samples observed to fail in ductile failure if compared to the worst samples. The later showed increment in the brittle like failure with the presence thicker and broader tearing lines with obvious cracking.

\section{Acknowledgement}

We would like to acknowledge the Fakulti Kejuruteraan Pembuatan, Universiti Teknikal Malaysia Melaka and HML Auto Industries (M) Sdn Bhd for the support and assistance in realizing this study. 


\section{References}

[1] Jasvir Singh Dhillon, Priyanka Rao and V.P. Sawant, "Design of Engine Mount Bracket for a FSAE Car using Finite Element Analysis," Int. Journal of Engineering Research and Applications 4, no. 9-6 (2014), 74-81.

[2] Yunhe YuNagi, G Naganathan and Rao V Dukkipati, "Literature Review of Automotive Vehicle Engine Mounting Systems," Mechanism and Machine Theory 36, no.1 (2001): 123-142.

[3] A. S. Sathawane and A. V. Patil, "Analytical Study of Engine Mount to Suit the Damping Requirements of Engine," International Journal of Latest Trends in Engineering and Technology 3, no.3 (2014): 7-11.

[4] Reza Tikani, Nader Vahdati and Saeed Ziaei-Rad, "Two-Mode Operation Engine Mount Design for Automotive Applications," Shock and Vibration 19, no.6 (2012): 1267-1280.

[5] A. J. Martyr and M. A. Plint, "The Design, Building, Modification and Use of Powertrain Test Facilities" in Engine Testing (San Diego : Butterworth-Heinemann 2012), 203-225.

[6] Fadi Alkhatib, "Techniques for Engine Mount Modeling and Optimization" (PhD Thesis, University of Wisconsin, 2013).

[7] Ali Masih Hosseini, “A Solenoid-Based Active Hydraulic Engine Mount : Modelling, Analysis, and Verification” (MASc Thesis, Simon Fraser University, 2010).

[8] R.Singh, "Dynamic Design of Automotive Systems: Engine Mounts and Structural Joints," Sādhanā 25, no.3 (2000): 319-330.

[9] D. Santosh Kumar, M. RaviTeja Reddy, Jayakumar Vijayarangam, C. Sai Virinchy and A. Hafeez Asif, "Studies on Design and Material Aspects of IC Engine Mounts for Vibration Reduction," International Journal of Pure and Applied Mathematics 118, no. 9 (2018): 355-366.

[10] S. Kamaruddin, A. F. Ramly, N. Mohd Shukri, A.G. Bakri and Q.Fourrier, "Evaluation of Specialty Natural Rubbers for Engine Mount Application," IOP Conf. Series: Materials Science and Engineering 548, (2019): 012004.

[11] Wang Peng, Su Zhengtao, Lai Liangqing, Jiang Honggang and Wang Jinghe, "Engine Isolate Mount Elastomers" (PDF, 2015 International Conference on Structural, Mechanical and Material Engineering, Dalian, China, November 0608, 2015).

[12] Maciej Sienkiewicz, Helena Zofia Janik, Kaja Borzędowska-Labuda and Justyna Kucińska-Lipka, "Environmentally Friendly Polymer-Rubber Composites obtained from Waste Tyres: A Review," Journal of Cleaner Production 147, (2017): 560-571.

[13] Atul Adhau, and Prof V. Kumar, "Engine Mounts and its Design Considerations," International Journal of Engineering Research \& Technology 2, no. 11 (2013): 763-769.

[14] David S. Mukooza, "Understand the Car Engine Mount," Daily Monitor, Accessed February 7, 2020. https://www.monitor.co.ug/Business/Auto/Understand-car-engine-mount/688614-4388548-smy5eb/index.html.

[15] A.M. NoorAzammi, S.M. Sapuan, M. R. Ishak, Mohamed T. H. Sultan, "Conceptual Design of Automobile Engine Rubber Mounting Composite using TRIZ-Morphological Chart-Analytic Network Process Technique," Defence Technology 14, no. 4 (2018): 268-277.

[16] Noraiham Mohamad, Juliana Yaakub, Jeefferie Abd Razak, Mohd Yuhazri Yaakob, Mohammed lqbal Shueb and Andanastuti Muchtar, "Effects of Epoxidized Natural Rubber ( ENR-50) and Processing Parameters on the Properties of NR / EPDM Blends Using Response Surface Methodology," Journal of Applied Polymer Science 131, no. 17 (2014): 40713 (1-8).

[17] Juliana Yaakub, "Synthesis and Physico-Mechanical Analysis of Graphene Nanoplatelets (GNPs) Filled Natural Rubber/Ethylene Propylene Diene Monomer (NR/EPDM) for Vibration Resistance" (MSc Thesis, Universiti Teknikal Malaysia Melaka, 2015).

[18] K. C. Lee, N. A. Md Yusoff, N. Othman and N. A. Mohamad Aini, "Effect of Vulcanization Temperature On Curing Characteristic, Physical and Mechanical Properties of Natural Rubber/Palygorskite Composites," IOP Conference Series: Materials Science and Engineering 223, (2017): 012017(1-11).

[19] Maha Zaghdoudi, Anja Kömmling, Matthias Jaunich and Dietmar Wolff, "Scission, Cross-Linking, and Physical Relaxation during Thermal Degradation of Elastomers," Polymers 11, no. 8 (2019): 1280(1-12).

[20] Indra Surya, L. Sukeksi and N. Hayeemasae, "Studies on Cure Index, Swelling Behaviour, Tensile and Thermooxidative Properties of Natural Rubber Compounds in the Presence of Alkanolamide," IOP Conference Series: Materials Science and Engineering 309, (2018): 012060(1-6).

[21] Noraiham Mohamad, Andanastuti Muchtar, Mariyam Jameelah Ghazali, Dahlan Hj. Mohd and Che Husna Azhari, "Correlation of Filler Loading and Silane Coupling Agent on the Physical Characteristics of Epoxidized Natural Rubber-Alumina Nanoparticles Composites." Journal of Elastomers \& Plastics 42, no.4 (2010); 331-346. 